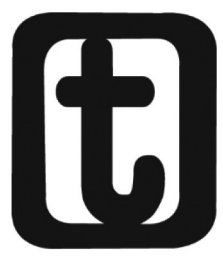

\title{
MOVIMENTOS SOCIAIS E SERVIÇO SOCIAL: termos do debate
}

SOCIAL MOVIMENTS AND SOCIAL SERVICE: TERMS OF DEBATE

\author{
Maria Lúcia Duriguetto ${ }^{1}$ \\ Raphael Dutra Bazarello²
}

\section{RESUMO}

O artigo apresenta uma sistematização dos conteúdos dos artigos publicados na Revista Serviço Social e Sociedade sobre a temática das organizações e das lutas sociais. Nosso objetivo é apresentar os termos do debate desenvolvidos nas produções do período 1979-2013. Uma das conclusões que explicitamos é que a intervenção do Serviço Social nos processos de mobilização e organização popular é pouco tematizada, sobressaindo-se tematizações sobre os espaços de participação institucional, notadamente os dos conselhos de direitos.

Palavras- Chave: Produção do conhecimento; Movimentos Sociais; Serviço Social.

\section{ABSTRACT}

The article presents a sistematization of contents of the articles published in Revista Serviço Social e Sociedade about the social struggles theme. The objective is to present the terms of the developed debates in the period 19792013 productions. One of the conclusions that we underline is that the Social

1 Professora doutora da Faculdade de Serviço Social da Universidade Federal de Juiz de Fora. Bolsista Produtividade em Pesquisa do CNPq.

2 Graduando em Serviço Social pela Faculdade de Serviço Social-Universidade Federal de Juiz de Fora e bolsista PIBIC. 


\section{tempordlis}

Service intervention in the processes of mobilization and popular organization is few discussed, standing out the reflections on the spaces of institutional participation, notably the rightscouncils.

Key-words: Knowledge production; Social Movements; Social Service.

Submetido - 15/03/2015

Aceito - 23/05/2015

\section{INTRODUÇÃO}

O contexto sociopolítico brasileiro do final da década de 1970 e da década de 1980 caracterizou-se pela proliferação de movimentos e organizações sociais que deram visibilidade pública e política às diferentes expressões da "questão social", como o "novo sindicalismo" e os movimentos e lutas por políticas sociais setoriais. Algumas reivindicações foram, em parte, inscritas na Carta de 1988. Entretanto, a partir da entrada dos anos 1990,temos a adoção, pelos governos nacionais, da política de ajustes neoliberais que impactaram regressivamente os processos de mobilização e organização sindical e popular bem como a possibilidade da criação de políticas públicas universais. No Serviço Social temos, também a partir desta década, a consolidação do projeto ético-político profissional que, em sua totalidade, se antagoniza com as diretivas socioeconômicas do receituário neoliberal e afirma uma sintonia com as demandas, necessidades e projetos societários advindos das lutas das classes subalternas.

O objetivo do presente artigo é explicitar os termos do debate desenvolvidos nos artigos publicados na Revista Serviço Social e Sociedade entre os anos 1979-2013 sobre os temas da participação, organizações e lutas sociais e a relação do Serviço Social nestes processos. Sistematizaremos o conteúdo exposto nos artigos em cinco eixos, nos quais condensam e expressam os debates dos temas, que foram definidos com base na centralidade do tratamento dos seus conteúdos em períodos definidos.

\section{MOVIMENTOS SOCIAIS: EMERGÊNCIA, RELAÇÃO COM O ESTADO E A QUESTÃO DA ASSESSORIA}

Estes temas foram centrais nos artigos publicados entre 1979 a 1996. As bases teóricas das análises explicitadas acerca da emergên- 
cia e impactos sociopolíticos dos movimentos sociais estão nas produções de Jean Lojkine, Manuel Castells, Alain Touraine e Tilman Evers. O pensamento do marxista italiano Antônio Gramsci é incorporado, em diversos artigos, como a matriz teórica fundamental das análises em interlocução ou não com o pensamento dos autores anteriormente citados $^{3}$. Os artigos evidenciam que a concepção de Lojkine e Castells acerca da emergência dos movimentos sociais reside no nível estrutural, sendo apreendidos como expressões das formas de manifestação das lutas de classe que incidem sobre o salário indireto por este ser insuficiente à reprodução da força de trabalho. Nesta concepção, ressalta-se a necessidade dos movimentos estarem articulados com outras organizações, como partidos políticos, para emergência, conforme desenvolve Gramsci, de uma contra-hegemonia.

Nos artigos que incorporam as concepções de Touraine e Evers, os movimentos são tidos como fenômenos novos, centrados na esfera do consumo, espontâneos, autônomos e heterogêneos quanto à composição social, tendo um potencial transformador que se situa no plano sociocultural.

Foram desenvolvidas análises que pontuaram críticas à incorporação das formulações de Castells e Lojkine, por não considerarem as especificidades da nossa formação capitalista tardia e dependente e as configurações diferenciadas assumidas pelo aparato estatal. Enfatizou-se que a predominância do enfoque na interação opositiva (cooptação ou destruição) dos movimentos sociais com o sistema institucional acabou limitando as investigações à dinâmica interna dos movimentos, enfatizando-se seu voluntarismo, espontaneísmo, autonomia e caráter inovador e transformador.

A emergência dos movimentos sociais na realidade brasileira é situada, pela maioria dos artigos, a partir da década de 1970, no contexto das lutas contrárias ao modelo de desenvolvimento econômico. Os autores definem a causalidade da emergência dos movimentos pela defesa dos direitos a bens de consumo coletivo e direitos políticos. É destacada a diferencialidade dos movimentos em relação aos seus projetos políticos societários; dinâmica interna; articulação entre base e liderança; relações com assessorias políticas, religiosas,

3 Não é nosso objetivo aqui explicitar o pensamento destes autores e nem nossa análise das reflexões desenvolvidas sobre eles, mas apenas apresentar que elementos de suas elaborações são incorporados e desenvolvidos nos artigos. 


\section{temporalis}

militantes de partidos, agentes do Estado.

Algumas análises assinalaram que o fato de os movimentos se ligarem a lutas tanto da esfera da produção quanto da reprodução possibilitaria a visualização da totalidade da dominação. O potencial político das lutas dependeria da articulação com outras organizações da sociedade civil, estabelecendo alianças que lhes garantam vínculos de suas lutas pontuais com forças socio-políticas mais universalizantes.

Para outros autores, é necessário recorrer à trajetória organizativa da classe operária desde os primeiros anos do século XX, pois esta teria sido a matriz das diversas formas de ações coletivas no meio urbano que propiciaram o desenvolvimento dos movimentos sociais. Considera-se que os movimentos são heterogêneos quanto à sua base social, afetando amplos setores da população, além do operário tradicionalmente mobilizado. Os movimentos derivariam de contradições específicas e, mesmo que se articulem às relações de produção, não poderiam ser reduzidos às relações de classe. No que tange à sua composição, o referente se concentra nos setores populares, cuja concretude ocorre no nível do consumo coletivo por meio das alternativas que criam para reproduzirem e transformarem suas condições de trabalho e de vida. O parâmetro que define os setores populares não se reduz à inserção direta no processo produtivo, mas considera também suas experiências práticas de luta contra diversas formas de exploração e dominação presentes no seu cotidiano, sendo nessas lutas que os sujeitos se constituem.

A maioria das análises produzidas entre 1979-1996 pondera que o aparato estatal teria contribuído para desarticular os movimentos sociais e reduzir seu potencial reivindicatório utilizando-se da burocracia, do diálogo e da conciliação para transformar a participação em cooptação. Outras reflexões partem da mesma avaliação, mas assinalam que as experiências dos movimentos no convívio direto com o aparato estatal pode também contribuir para sua politização.

Em relação aos impactos sociopolíticos, assinalam que os movimentos sociais podem contribuir para a crítica às formas tradicionais de reivindicação, calcadas no clientelismo, no paternalismo, negando vinculações com o aparato estatal e alianças com partidos políticos. Mas, sobretudo, os movimentos expressariam as questões do cotidiano, especialmente aquelas que se relacionam com a renova- 
ção dos padrões socioculturais.

Ao que tange às relações dos movimentos sociais com as assessorias, há referências que tratam de relativizar a autonomia dos movimentos, sustentando-se na necessidade do agente externo na mobilização e organização dos setores populares, considerando-o como indutor dos rumos dos processos de luta e organização. Explicitam que a autonomia prende-se à elaboração da própria identidade e de projetos de mudança social com base nas próprias experiências dos sujeitos, mas não deve supor isolamento e basismo, sendo necessárias articulações e alianças com outras organizações da sociedade civil. Algumas análises exploraram o papel das Comunidades Eclesiais de Base (CEBs) nos anos 1970, das pastorais e da Teologia da Libertação, explicitando a dimensão educativa que a assessoria assume junto aos setores populares, buscando a transformação do seu modo de ver e agir, a articulação e o desenvolvimento das lutas a partir de situações vivenciadas no cotidiano.

No que se refere aos partidos políticos, há análises que explicitam que estes e os movimentos são instrumentos distintos de luta dos trabalhadores. Os militantes partidários captam as experiências e reivindicações, transformando-as em propostas políticas que, elaboradas e sistematizadas, são devolvidas aos movimentos. Ressalta-se que um partido político é muito mais amplo e tem propostas mais globais para a sociedade do que um movimento.

\section{CLASSE TRABALHADORA, MOVIMENTO SINDICAL E ORGANIZAÇÃO POLÍTICA DO SERVIÇO SOCIAL}

As transformações do mundo do trabalho e seus impactos nas relações de trabalho e na organização sindical são temas abordados nos artigos pós-segunda metade da década de 1990. Os artigos explicitam a complexidade das formas de uso, contratação e dispensa da força de trabalho ensejada pelo padrão de acumulação flexível, que produziram uma maior heterogeneidade da classe trabalhadora. Um artigo, em específico, trata da configuração das lutas sociais no contexto atual da crise do capital, explicitando as principais linhas do debate da configuração dos sujeitos, instrumentos organizativos e projetos societários. No campo da análise das lutas sindicais, há reflexões que debatem a estratégia da redução da jornada de trabalho, em que encontramos posições de que essa luta efetiva conquistas para os trabalhadores e posições que destacam a lógica reformista dessa estratégia, por abandonar o debate e as ações que visem a superação 


\section{temporalis}

da sociedade de classes.

Há análises do chamado "novo sindicalismo" e dos impactos regressivos dos ajustes neoliberais para a ação sindical. É explicitado que, pós-anos 2000, tem-se o desenvolvimento de uma postura adesista dos sindicatos, antes vinculados a um projeto de classe, à lógica governista. Os artigos apresentam a necessidade do retorno ao sindicalismo combativo, que defenda os reais interesses da classe trabaIhadora e que desenvolva ações na direção da emancipação humana.

Encontramos significativas reflexões acerca da relação entre Serviço Social e as lutas sindicais. O contexto dos finais dos anos 1970 de rearticulação dos movimentos e do "novo sindicalismo" são analisados como impulsionadores dos assistentes sociais a se organizarem dentro dos sindicatos. São tematizados: o contexto histórico do III Congresso Brasileiro dos Assistentes Sociais, em 1979; a rearticulação dos movimentos sociais; processo de abertura política; vinculação da vanguarda profissional com as lutas sociais; influência da tradição marxista na profissão. É explicitado que o processo que se iniciou a partir do "congresso da virada" e a articulação e aproximação com os movimentos sociais e os sindicatos constituiu um marco para o desenvolvimento do projeto ético-político profissional nos anos 1990. É neste processo que os artigos analisam o debate pela extinção dos sindicatos por setor profissional e pelo estímulo à criação dos sindicatos por setor econômico, bem como o processo de criação da Confederação Nacional dos Assistentes Sociais (Fenas). Explicitam que esta entidade representa um retrocesso, uma vez que pode contribuir para uma maior fragmentação das demandas profissionais, tornando-as corporativistas.

Também encontramos reflexões acerca da luta desenvolvida pelo Conselho Federal de Serviço Social (CFESS) em relação à jornada das 30 horas para os assistentes sociais; da centralidade da Associação Brasileira de Ensino e Pesquisa em Serviço Social (ABEPSS) e do CEFESS na constituição do projeto ético-político profissional. Um artigo abordou o movimento estudantil no Serviço Social (MESS) e as relações da Executiva Nacional dos Estudantes de Serviço Social (ENESSO) com o movimento estudantil nacional e a importância deste espaço para a consolidação do projeto ético-político profissional. 


\section{CONSELHOS DE DIREITO, FÓRUNS TEMÁTICOS E MOVIMENTOS SOCIAIS}

A tematização dos conselhos gestores de políticas públicas é central nas produções a partir da segunda metade dos anos 1990. A maioria das análises aborda os conselhos como uma conquista dos movimentos sociais, que objetiva conferir níveis crescentes de publicização no âmbito das políticas sociais.

Em outras análises (principalmente na área da saúde e assistência social), parte-se da contextualização da agenda de contrarreformas do Estado e seus impactos regressivos na constituição das políticas sociais e, não obstante a positividade da novidade conselhista, são problematizadas questões relativas à centralização do poder no executivo e sua capacidade para neutralizar, impedir e desarticular a ação dos conselhos; diluição dos conflitos e dos enfrentamentos; sua natureza setorial e fragmentada; tendência à burocratização dos processos participativos; decisões tomadas sob o crivo corporativista; sonegação de informações relativas ao orçamento, dentre outros. E, como proposições, destacam-se a necessidade de uma maior articulação entre os conselhos e maior participação dos movimentos sociais e entidades que representem os interesses populares; maior controle dos representados sobre os conselheiros; formação e qualificação dos conselheiros e publicização de suas ações.

Há artigos que enfatizam, partindo da análise gramsciana da relação entre Estado e sociedade civil, que o controle social exercido pelos conselhos deverá ser norteado por um projeto societário das classes subalternas e pela busca da construção de uma nova hegemonia.

Outras análises destacaram o surgimento de novos mecanismos de controle democrático como os fóruns e a frente nacional contra a privatização da saúde, que têm exercido pressão sobre os mecanismos institucionais de controle social - conselhos e conferências - para que se posicionem contra os novos modelos de gestão na saúde.

Há análises que se centraram na criação do I Fórum Social Mundial, caracterizado como um espaço de reação à globalização neoliberal e de denúncia e resistência ao capitalismo.

Em relação aos movimentos sociais, encontramos sua tema- 


\section{temporalis}

tização em reflexões que se ativeram na constituição e caracterização de suas lutas específicas. Uma reflexão abordou o processo histórico de constituição dos movimentos sociais em favelas, que reivindicam junto ao Estado o atendimento de suas demandas. É neste contexto que surgem as associações de moradores como mediadoras entre as lutas da população e o Estado, vindo a se constituírem no conduto institucional por intermédio do qual a população se expressa e faz valer seus interesses em face ao Estado. As associações também vêm se constituindo em operadoras de programas sociais, o que contribui para a legitimidade governamental perante a população. A consequência desta relação é que as associações não recorrem mais à participação da população para conquistar os benefícios almejados, passando agora a vigorar o prestígio de seus dirigentes junto ao poder público, configurando novas formas de clientelismo e de perda da autonomia.

O movimento estudantil é abordado no contexto histórico de Maio de 1968, sendo analisado como uma forma de resistência contra as práticas discriminadoras, opressivas e autoritárias, configurando um novo estilo de mobilização e contestação social. Suas pautas reivindicativas não se restringiram às do trabalho e da luta de classes, mas na cultura, na luta pela democracia, na contestação do modelo hierárquico autoritário de família e as expressões da sexualidade. Outros três movimentos foram abordados: os Sem-teto nos Estados Unidos, o Movimento Indígena no México e o Movimento Feminista. Neste, foram tematizadas as lutas das mulheres em expor e modificar suas condições de opressão e de pouco acesso aos direitos políticos.

\section{SOCIEDADE CIVIL E O DEBATE DO “TERCEIRO SETOR”}

Neste eixo, os artigos desenvolvidos a partir da década de 1990 abrangem temáticas referentes ao chamado processo de "onguização"; aos diferentes significados e papéis atribuídos ao chamado "terceiro setor". As abordagens destacam a emergência e o desenvolvimento do "terceiro setor" como parte da estratégia neoliberal de redução de gastos sociais pelo Estado, passando à sociedade civil - transmutada em "terceiro setor" - a função de dar respostas às diversas expressões da questão social. Em sintonia com as políticas neoliberais, as ONGs configuraram uma estratégia de transferir para a sociedade a atribuição de atividades próprias do Estado.

Mas há abordagens que incorporam o conceito de "terceiro 
setor" como um conjunto de organizações e iniciativas privadas que visam à produção de bens e serviços públicos. As ONGs, em algumas análises desenvolvidas nos artigos publicados na década de 1980, são analisadas como novos canais institucionais de participação das classes médias na esfera pública, exercendo as funções de articulação de interesses e demandas dos setores populares nas arenas institucionais e de confronto e negociação dos conflitos sociais.

Há reflexões que abordam os diferentes significados e papéis atribuídos à sociedade civil presentes no debate acadêmico e nos projetos prático-políticos. Objetiva-se resgatar a categoria sociedade civil tal como a formula o marxista italiano A. Gramsci, que a conceitua como uma esfera da disputa de projetos societários pelas organizações e movimentos das classes sociais. Este resgate vem para se contrapor à transformação ideológica da sociedade civil em "terceiro setor" como esfera da ação "solidarista”, filantrópica, voluntária.

Também encontramos tematizações acerca do "novo associativismo", fenômeno que se desenvolveu nos anos 1990 no cenário de organização e de manifestações populares contra o desemprego e privatizações de empresas estatais. É ressaltado que os fenômenos associativos foram construídos a partir da mobilização da população organizada em redes interativas e apresentam perfil político-ideológico plural, não surgem de processos de mobilização de massa, mas de processos de mobilizações pontuais conforme a causa em que os atores coletivos se identificam. Neste contexto, ressalta-se a identificação com um campo de análise dos movimentos sociais - tidos como "associativismo civil" - baseada em conceitos como identidade coletiva e política e redes sociais. Defende-se que as diferentes formas de associativismo articulam-se por critérios identitários na esfera pública gerando a formação de um ativismo fundamentado nos valores da democracia, da solidariedade e da cooperação entre os excluídos.

O acelerado crescimento do "terceiro setor" a partir da década de 1990 é apreendido como demanda emergente para atuação do Serviço Social. Há referência em relação à análise da experiência do Serviço Social numa ONG, em que a questão central é a contradição no que diz respeito ao fato dos assistentes sociais reconhecerem o espaço das ONGs como esvaziamento dos direitos sociais, ao mesmo tempo em que, enquanto um trabalhador assalariado, não tem condições de recusar sua inserção nesse campo sócio-ocupacional. É salientada a necessidade de os assistentes sociais perspectivarem 


\section{temporalis}

estratégias de atuação que assegurem a defesa e a reivindicação dos direitos sociais nesses espaços.

\section{INTERVENÇÃO PROFISSIONAL DO SERVIÇO SOCIAL NOS MOVIMENTOS E ORGANIZAÇÕES POPULARES}

Nos artigos que versam acerca da intervenção do assistente social nos processos de mobilização e organização popular, produzidos entre 1979-1996, são evidenciados alguns eixos de propostas interventivas como educação popular; assessoria aos movimentos sociais; e a função de intelectual orgânico do assistente social ${ }^{4}$. No campo da educação popular, as reflexões consideram que o assistente social deva assessorar as organizações das classes subalternas nas conquistas de direitos de cidadania por meio da troca de conhecimentos e experiências com a população com a qual se trabalha para a construção do "saber popular". As reflexões apontam que é necessário que os profissionais se aproximem dos movimentos sociais, colocando-se "a serviço" deles, se colocando como agentes da "educação popular". Incorpora-se a categoria de "intelectual orgânico", de Gramsci, para a compreensão do assistente social como "organizador", "dirigente" e "técnico", destacando o papel do agente profissional na sua dimensão propriamente política.

No período 1996-2013, encontramos um artigo que trata da intervenção dos assistentes sociais nos conselhos, particularmente no da assistência social, em que se defende a necessidade de uma intervenção mais qualificada dos profissionais no campo político - em que deve impulsionar e ampliar o movimento social que se organiza em torno da defesa da política social; e teórico - adensar a produção teórica articulada à análise de tendências macrossocietárias para a criação de estratégias de intervenção.

Dois artigos abordam a metodologia da educação popular, explicitando os elementos centrais que a fundam com base na contribuição de Paulo Freire. Discorrem sobre a adoção, pelo assistente social, da "metodologia" da educação popular na intervenção - valori-

4 Esses eixos também foram identificados na pesquisa realizada por Silva e Silva (1995) na literatura do Serviço Social (produção dos Programas de Pós-Graduação, anais e relatórios de eventos e congressos promovidos pela ANAS e ABESS; livros e artigos da Revista Serviço Social e Sociedade na década de 1980 e 1990. 
zação do saber popular, mediante o respeito à autonomia dos sujeitos e construção com eles de alternativas de intervenção - e no espaço da formação profissional. Um dos artigos exemplifica esta incorporação em uma experiência extensionista no campo da saúde.

Os cinco eixos temáticos explicitados ao logo deste artigo podem ser visualizados abaixo de acordo com o número de produções.

Produção dos artigos na Revista Serviço Social e Sociedade no período 1979-2013

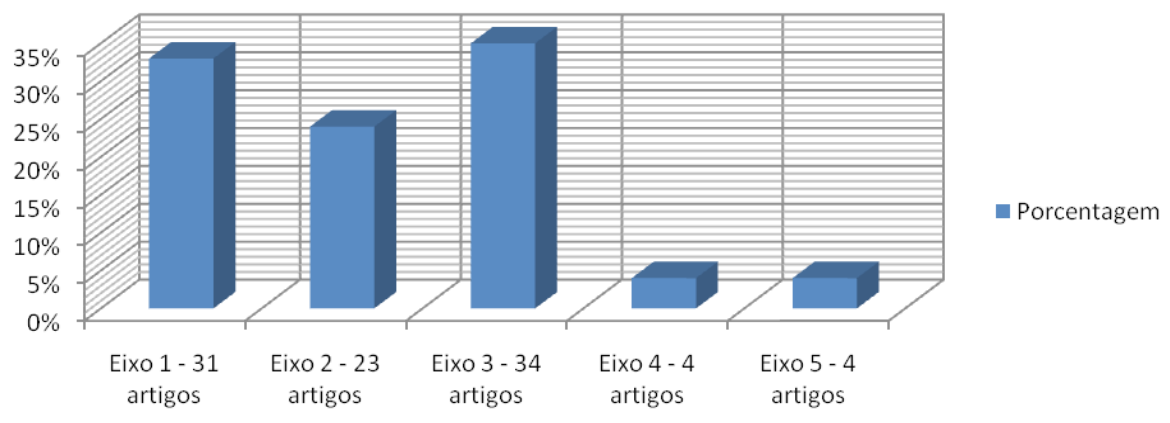

Fonte: Duriguetto, Ma. L. e Bazarello, R.D. "Serviço Social nos processos de organização e mobilização popular”. Relatório de Pesquisa. FSS/UFJF, 2014.

\section{CONSIDERAÇÕES FINAIS}

Pelo exposto, podemos perceber que os artigos publicados entre 1979 e a primeira metade dos anos 1990, tematizaram aspectos concernentes aos processos de emergência e desenvolvimento dos movimentos sociais presentes na cena pública nacional neste período. Assume destaque as caracterizações dos seus aspectos constitutivos - sujeitos que os compõem; relação com o Estado, partidos e projetos societários perspectivados. Esse debate é realizado nos termos analíticos de Castells, Lojkine e Gramsci ou de Touraine e Evers. Os eixos centrais do debate postos com base nessas referências teóricas são: a) a relação entre produção e reprodução da vida social e as formas de organização e de lutas existentes nessas esferas (movimento operário e movimentos sociais), em cujas análises ora acentuam a ne- 


\section{temporalis}

cessária relação e articulação das instâncias organizativas e de lutas, ora tendem a se ater na especificidade das organizações e lutas que se desenvolvem na esfera da reprodução; b) a relação do Estado com os movimentos sociais, que polarizou o debate entre interpretações que assinalam o caráter de conflito dos movimentos com o aparato estatal e as que valorizam a perspectiva da negociação e da institucionalização das reivindicações; c) o caráter autônomo e espontâneo do surgimento dos movimentos sociais ou a valorização dos assessores ou agentes externos na sua dinâmica formativa, cuja questão central é a valorização das lutas específicas ou a prospectiva de articulação das organizações e movimentos por instâncias políticas universalistas, como o partido político.

É nos anos da década de 1980 que encontramos o desenvolvimento de análises sobre a intervenção profissional do assistente social nas lutas e movimentos sociais. Como nosso levantamento revelou, esse debate esteve presente em um número reduzido de artigos. Nestes, ressalta-se, como eixos centrais das reflexões, a incorporação, pelo Serviço Social, da metodologia da educação popular e o reconhecimento do assistente social como um intelectual orgânico. Ao que tange às análises que reclamam o uso da educação popular e a identificação do assistente social como um educador popular ou intelectual orgânico, evidenciamos que a educação popular foi criada e desenvolvida, a partir dos anos 1960, pelos movimentos sociais, como tática e/ou estratégia constitutiva de seus militantes e a eles diretamente vinculada. Já a categoria de intelectual orgânico, de Gramsci, tem seu conteúdo organicamente relacionado à ação da militância partidária na criação de condições sociopolíticas e culturais para a construção de processos contra-hegemônicos ao do capital. A mediação da categoria de intelectual orgânico com os projetos e as ações profissionais necessita ser mais bem apreendida e problematizada5. Assim, a incorporação direta da educação popular e da categoria de intelectual orgânico pelo Serviço Social tende a dificultar o estabelecimento da distinção entre a prática profissional e a prática militante.

Nos artigos analisados no pós-segunda metade dos anos 1990, verificamos, ao contrário das análises da década de 1980, uma exígua tematização das diferentes abordagens teóricas dos movimen-

5 Cf. a certeira definição de Netto (1999) entre projeto societário e projeto profissional. Um tratamento do tema dos intelectuais no pensamento de Gramsci pode ser encontrado em Duriguetto (2014). 
tos e lutas sociais. A prevalência analítica é a do tratamento dos espaços institucionais de participação, sobretudo os conselhos de direitos, tematizando-os nas suas positividades, limites e desafios. As tematizações são feitas no contexto de análises que apontam os processos de contrarreformas neoliberais no campo social e seus impactos negativos para a criação de políticas sociais universais e de qualidade, objetivo que orientaria a criação dos espaços conselhistas. Sobressaem, também, tematizações acerca do chamado "terceiro setor", no qual estão inseridas as reflexões acerca das ONGs, com análises que destacam tanto a novidade positiva deste "suposto" espaço de ação "não estatal" quanto análises que o relaciona com as estratégias neoliberais de transferência para este espaço as responsabilidades de operacionalização de políticas e serviços. No campo das resistências, para além de algumas análises que dotam os conselhos da possibilidade de nele se incluírem, temos o destaque dos espaços extrainstitucionais dos fóruns de políticas ou de resistência mundial. O que nos chama a atenção é o desenvolvimento reduzido de análises acerca dos espaços extrainstitucionais das lutas e movimentos sociais ${ }^{6}$. As análises que aqui se atêm se concentram no movimento sindical, especialmente nos contornos governistas assumidos pela ação sindical nos governos petistas, sendo apenas dois movimentos sociais nacionais tematizados. Também destacamos a adoção, em dois artigos, de referenciais conceituais antagônicos para a análise dos movimentos sociais: um marxista, que enfatiza a centralidade da classe e das lutas de classe e um pós-moderno, que adota as teorias culturalistas e identitárias.

O Serviço Social, nas suas relações com os processos organizativos dos trabalhadores, é tematizado pela via do debate dos processos de criação e ruptura com suas organizações sindicais profissionais, bem com a centralidade das organizações da categoria na construção e consolidação do projeto ético-político profissional. Não encontramos nenhuma análise, no período em tela, que trata especificamente da relação do Serviço Social com os movimentos e organizações das classes subalternas e que trata da intervenção profissional

6 Verificamos, assim, a centralidade de um enfoque analítico no espaço institucional da discussão das políticas, o que produz uma secundarização do conhecimento das formas de organização, dos processos de formação de ações coletivas, de demandas e de lutas que não se desenvolvem para além de sua expressão nos espaços institucionais. 


\section{tempordlis}

nesses espaços ${ }^{7}$ Apenas um artigo, que trata dos espaços conselhistas, faz menção à intervenção profissional. Como nos artigos da década de 1980, encontramos a tematização da relação da profissão com os processos de mobilização e organização popular pela via da adoção da "metodologia" da educação popular. Como exposto anteriormente, as reflexões sobre a educação popular e de sua relação com o Serviço Social necessitam de maior aprofundamento. É necessário debatermos as diferentes concepções de educação popular e problematizarmos sua transposição direta, como "metodologia", para a intervenção profissional nos diferentes espaços sócio-ocupacionais.

\section{REFERÊNCIAS}

ABRAMIDES, M. B. C. A organização político-sindical dos assistentes sociais: trajetória de lutas e desafios contemporâneos. Serviço Social \& Sociedade, São Paulo, n. 97, p. 85-108, out./dez. 2009.

; CABRAL, M. do S. R. O significado do papel político do III Congresso Brasileiro de Assistentes Sociais - CBAS - 1979. Serviço Social \& Sociedade, São Paulo, n. 100, p. 728-739, out./dez. 2009.

ABREU, M. M. A questão pedagógica e a hegemonia das classes subalternas: aportes da análise gramsciana. Serviço Social \& Sociedade, São Paulo, ano 17, n. 51, p. 61-74, 1996.

; CARDOSO, F. G.; RIBEIRO, M. A. F. Movimentos populares: algumas questões emergentes na constituição de sujeitos coletivos. Serviço Social \& Sociedade, São Paulo, n. 39, p. 31-61, 1992.

. ABEPSS: a perspectiva da unidade da graduação e a produção do conhecimento na formação profissional. Serviço Social \& Sociedade, São Paulo, n. 95, p. 173-188, 2008.

ALMEIDA, C.; TATAGIBA, L. Os conselhos gestores sob o crivo da política: balanços e perspectivas. Serviço Social \& Sociedade, São Paulo, n. 109, p. 68-92, jan./mar. 2012.

7 Silva (2009, p.615) também constata o significativo decréscimo da produção sobre o tema nos artigos da Revista Serviço Social e Sociedade. A produção é de 6,6\% do total da produção nos anos 1979/1989, 5,4\% nos anos 1989/1999 e apenas 1,7\% nos anos 2000/2009. 
AMMANN, S. B. Movimentos sociais: unidade na diversidade. Serviço Social \& Sociedade, São Paulo, n. 36, p. 126-135, 1991.

ANTUNES, R. O desenho multifacetado do trabalho hoje e sua nova morfologia. Serviço Social \& Sociedade, São Paulo, v. 1, n. 69, p. 107120, 2002.

BAPTISTA, M. V. A participação como valor e como estratégia de ação do Serviço Social. Serviço Social \& Sociedade, São Paulo, n. 25, p. 21$29,1987$.

BASTOS, E. R. As classes subalternas e suas lutas. Serviço Social \& Sociedade, São Paulo, v. 6, n. 17, p. 41-48, 1985.

BAVA, S. C. Sobre o futuro da cidade de São Paulo, descentralização e participação: subprefeituras e conselhos de representantes. Serviço Social \& Sociedade, São Paulo, v. XXII, n. 66, p. 109-126, 2001.

BIDARRA, Z. S. Conselhos gestores de políticas públicas: uma reflexão sobre os desafios para a construção dos espaços públicos. Serviço Social \& Sociedade, São Paulo, ano XXVI, n. 88, p. 41-58, nov. 2006.

BRAVO, M. I. S. Desafios atuais do controle social no Sistema Único de Saúde (SUS). Serviço Social \& Sociedade, São Paulo, ano XXVI, n. 88, p. 75-100, nov. 2006.

- O significado político e profissional do congresso da virada para o Serviço Social brasileiro. Serviço Social \& Sociedade, São Paulo, n. 100, p. 679-708, 2009.

; CORREIA, M. V. Desafios do controle social na atualidade. Serviço Social \& Sociedade, São Paulo, n. 109, p. 126-150, 2012.

BRAZ, M.; MATOS, M. C. de. 30 anos de rearticulação do Movimento Estudantil em Serviço Social. Serviço Social \& Sociedade, São Paulo, n. 96, p. 174-182, 2008.

BOSCHETTI, I. Condições de trabalho e a luta dos(as) assistentes sociais pela jornada semanal de 30 horas. Serviço Social \& Sociedade, São Paulo, n. 107, p. 557-584, jul./set. 2011. 


\section{tempordlis}

BREDEMEIER, S. M. L. Conselho do idoso como espaço público. Serviço Social \& Sociedade, São Paulo, ano XXIV, n. 75 especial , p. 85-101, 2003.

CABRAL, E. H. de S. Espaço público e controle para a gestão social no terceiro setor. Serviço Social \& Sociedade, São Paulo, n. 86, p. 30-55, 2006.

CAMPOS, E. B. Assistência social: do descontrole ao controle social. Serviço Social \& Sociedade, São Paulo, v. 26, n.88, p. 101-121, jul. 2006.

; MACIEL, C. A. B. Conselhos paritários: o enigma da participação e da construção democrática. Serviço Social \& Sociedade, São Paulo, n. 55, p. 143-155, 1997.

CARDOSO, F. G. Os Movimentos Sociais populares no processo de transformação social. Serviço Social \& Sociedade, São Paulo, n. 33, p. 5-30, 1990.

COLARES, M. Aspectos da relação igrejas-centros de assessoria popular. Serviço Social \& Sociedade, São Paulo, n. 33, p. 45-60, 1990.

CONIL, E. M.; BRAVO, M. I. S.; COELHO, F. D. Políticas públicas e estratégias urbanas: o potencial político dos conselhos de saúde na construção de uma esfera pública democrática. Serviço Social \& Sociedade, São Paulo, n. 49, p. 98-116, 1995.

CFESS. Conselho Federal de Serviço Social. Serviço Social a caminho do século XXI: o protagonismo ético-político do conjunto CFESS-CRESS. Serviço Social \& Sociedade, São Paulo, n. 50, p. 172-190, 1996.

- O CFESS e os desafios político-profissionais do Serviço Social. Serviço Social \& Sociedade, São Paulo, n. 95, p. 190-201, 2008;

CORREIA, M. V. da C. A relação Estado/sociedade e o controle social: fundamentos para o debate. Serviço Social \& Sociedade, São Paulo, ano XXIV, n. 77, p. 22-45, 2004.

COSTA, A. E. S. Relato de uma prática no bairro da Vila Embratel (São Luís do Maranhão). Serviço Social \& Sociedade, São Paulo, n. 28, p. 12-25, 1988. 
COSTA, D. S. C. A (in) subordinação dos trabalhadores nas associações comunitárias. Serviço Social \& Sociedade, São Paulo, n. 39, p. 34-67, 1992.

CRISTO, S. C. A. de. Controle social em saúde: o caso do Pará. Serviço Social \& Sociedade, São Paulo, n. 109, p. 93-111, jan./mar. 2012.

DURIGUETTO, M. L. A questão dos intelectuais em Gramsci. Serviço Social \& Sociedade, São Paulo, n. 118, p. 265-293, abr./jun. 2014.

. Sociedade civil, esfera pública, terceiro setor: a dança dos con-

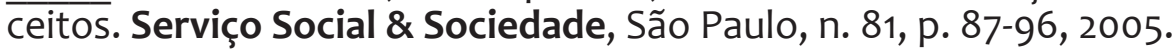

; SILVA Í.; DEBÓRTOLLI, D. Descentralização administrativa, políticas públicas e participação popular. Serviço Social \& Sociedade, São Paulo, n. 96, p. 5-25, 2008.

e BAZARELLO, R.D. Serviço Social nos processos de organização e mobilização popular. Relatório de Pesquisa . FSS/UFJF, 2014.

DURVALINA, M.; GOMES, M. de F. C. M. Sobre o caráter político das associações de moradores em favelas. Serviço Social \& Sociedade, São Paulo, n. 46, p. 17-29, 1994.

ESTANQUE, E. Movimentos sociais, classe e comunidade: reflexões sobre a sociedade portuguesa. Serviço Social \& Sociedade, São Paulo, ano XXII, n. 65, p. 54-77, 2001.

FERRAZ, A. T. R. Cenários da participação política no Brasil: os conseIhos gestores de políticas públicas. Serviço Social \& Sociedade, São Paulo, n. 88, p. 59-74, 2006.

FREIRE, L. M. de B. O. Movimentos sociais e controle social em saúde do trabalhador: inflexões, dissensos e assessoria do Serviço Social. Serviço Social \& Sociedade, São Paulo, n. 102, p. 289-313, abr./jun. 2010.

GOHN, M. da G. Movimentos populares urbanos e democracia. Serviço Social \& Sociedade, São Paulo, n. 17, p. 32-41, 1985.

- Movimentos sociais urbanos no Brasil: produção teórica e projetos políticos. Serviço Social \& Sociedade, São Paulo, n. 25, p. 7-21, 1987. 


\section{temporolis}

. Participação e gestão popular da cidade. Serviço Social \& Sociedade, São Paulo, n. 26, p. 25-47, 1988.

. Associações e mutirões comunitários: formas de organização popular. Serviço Social \& Sociedade, São Paulo, Ano IX, n. 28, 1988.

. Comunidade: a volta do mito e seus significados. Serviço Social \& Sociedade, São Paulo, v. 11, n. 32, p. 115-125, 1990.

. Estudo comparativo sobre três formas de organização popular. Serviço Social \& Sociedade, São Paulo, ano 11, n. 33, p. 27-34, 1990.

. Conselhos populares e participação popular. Serviço Social \& Sociedade, São Paulo, v. IX, n. 26, p. 25-47, 1990.

. O novo associativismo e o terceiro setor. Serviço Social \& Sociedade, São Paulo, v. 19, n. 58, p. 9-23, 1998.

GOMES, A. L. A nova regulamentação da filantropia e o marco legal do terceiro setor. Serviço Social \& Sociedade, São Paulo, ano XX, n. 61, p. 91-108, 1999.

GUIMARÃES, S. J. A questão do assistente social enquanto intelectual. Serviço Social \& Sociedade, São Paulo, n. 26, p. 120-146, 1988.

HERNÁNDEZ, J. G. V. Movimientos sociales para el reconocimiento de los movimentos indígenas y la ecologia política indígena. Serviço Social \& Sociedade, São Paulo, n. 94, p. 123-139, 2008.

JACOBI, P. Ação coletiva, atores sociais e cultura política. Serviço Social \& Sociedade, São Paulo, ano IX, n. 28, p. 48-69, 1988.

KRUSE, H. Movimentos sociais, participação popular e educação. Serviço Social \& Sociedade, São Paulo, n. 20, p. 28-34, 1986.

LIMA, B. A. Movimento social: a decodificação de um conceito. Serviço Social \& Sociedade, São Paulo, n. 22, p. 43-55, 1986.

LÜCHMANN, L. H. H.; SOUSA, J. T. P. de. Geração, democracia e globalização: faces dos movimentos sociais no Brasil contemporâneo. Serviço Social \& Sociedade, São Paulo, n. 84, p. 91-117, nov. 2005. 
MACHADO, A. M. B. Serviço Social e educação popular: diálogos possíveis a partir de uma perspectiva crítica. Serviço Social \& Sociedade, São Paulo, n. 109, p. 151-178, jan./mar. 2012.

MACHADO, G. S. Serviço Social nas ONGS no campo da saúde: projetos societários em disputa. Serviço Social \& Sociedade, São Paulo, n. 102, p. 269-288, abr./jun. 2010.

MARTINELLI, M. L. Alianças e consenso no Serviço Social - algumas reflexões à luz da perspectiva gramsciana. Serviço Social \& Sociedade, São Paulo, n. 22, p. 49-64, 1986.

MARTINS, R. S. et al. Pastoral operária e o movimento operário. Serviço Social \& Sociedade, São Paulo, n. 18, p. 89-110, 1985.

MONTAÑO, C. Das 'lógicas do Estado' às 'lógicas da sociedade civil': Estado e terceiro setor em questão. Serviço Social \& Sociedade, São Paulo, n. 59, p. 47-69, 1999.

MONTORO, T. S. Movimento social das mulheres. Serviço Social \& Sociedade, São Paulo, n. 24, p. 23-39, 1987.

NASCIMENTO, E. P. Crise e movimentos sociais: hipóteses sobre os efeitos perversos. Serviço Social \& Sociedade, São Paulo, ano XIV, n. 43, p. 71-92, dez. 1993.

PAULO NETTO, J. A construção do projeto ético-político contemporâneo. In: CAPACITAÇÃO em Serviço Social e Política Social: mod. 1. Brasília-DF: Cead: ABEPSS: CFESS, 1999.

. III CBAS: algumas referências para a sua contextualização. Serviço Social \& Sociedade, São Paulo, n. 100, p. 650-678, out./dez. 2009.

OSTERNE, M. do S. F.; GEHLEN, V. R. F. A condição paradoxal que constitui o feminismo: dilemas sobre igualdade e diferenças. Serviço Social \& Sociedade, São Paulo, v. 26, n. 84, p. 140-168, 2005.

PAIVA, B. A. de; COUTO, B. R.; TAPAJÓS, L. M. S. Fórum Social Mundial: 'movimento de movimentos' contra a barbárie neoliberal. Serviço Social \& Sociedade, São Paulo, v.1, n. 66, p. 49-75, 2001. 


\section{tempordlis}

PANIAGO, M. C. As lutas defensivas do trabalho: contribuições problemáticas à emancipação. Serviço Social \& Sociedade, São Paulo, n. 76, p. 78-92, 2003.

PAZ, R. O. Código de ética: reafirmar a função pública de conselheiros e conselheiras. Serviço Social \& Sociedade, São Paulo, n. 85, p. 117-122, 2006.

PINHEIRO, M. M. B. CNAS: consolidando o direito do cidadão. Serviço Social \& Sociedade, São Paulo, n. 88, p. 122-138, 2006.

PIRES, R. C. Participação e cooptação. Serviço Social \& Sociedade, São Paulo, n. 28, p. 33-47, 1988.

PONTES, L.; BAVA, S. C. As ONGS e as políticas públicas na construção do Estado democrático. Serviço Social \& Sociedade, São Paulo, ano XXVII, n. 50, p. 133-142, 1996.

PRATES, J. C. A democratização do poder local por meio do orçamento participativo da assistência social. Serviço Social \& Sociedade, São Paulo, n. 66, p. 91-108, jul. 2001.

RAICHELIS, R. Assistência social e esfera pública: os conselhos no exercício do controle social. Serviço Social \& Sociedade, São Paulo, v. XXIX, n. 56, p. 77-96, mar. 1998.

- Articulação entre os conselhos de políticas públicas: uma pauta a ser enfrentada pela sociedade civil. Serviço Social \& Sociedade, São Paulo, ano XXVII, n. 85, p. 109-116, 2006.

; PAZ, R. Fórum nacional de assistência social: novo marco de interlocução entre sociedade civil e governo federal. Serviço Social \& Sociedade, São Paulo, ano XX, n. 61, p. 110-131, 1999.

RAMOS, M. H. R. Para a crítica do paradigma dos movimentos sociais urbanos. Serviço Social \& Sociedade, São Paulo, v.1, n. 44, p. 71-92, 1994.

RAMOS, S. R. Organização política dos(as) assistentes sociais brasileiros(as): a construção histórica de um patrimônio coletivo na defesa do projeto profissional. Serviço Social \& Sociedade, São Paulo, ano XXVIII, n. 88, p. 160-181, 2006. 
; SANTOS, T. R. M. dos. Dilemas e desafios do movimento sindical brasileiro: a particularidade da organização dos(as) assistentes sociais. Serviço Social \& Sociedade, São Paulo, ano XXIX, n. 94, p. 38-59, 2008.

RIBEIRO, L. Como pensar os movimentos de saúde? Serviço Social \& Sociedade, São Paulo, n. 29, p. 31-42, 1989.

RIBEIRO, M. O caráter pedagógico dos movimentos sociais. Serviço Social \& Sociedade, São Paulo, n. 58, p. 41-71, 1998.

ROSA C. M. M; RAICHELIS, R. O serviço social e os movimentos sociais - análise de uma prática. Serviço Social \& Sociedade, São Paulo, ano III, n. 19, p. p. 74-97, 1985.

SANTOS, S. M. O CFESS na defesa das condições de trabalho e do projeto ético-político profissional. Serviço Social \& Sociedade, São Paulo, n. 104, p. 695-714, out. dez. 2010.

SANTOS, V. N. Terceiro setor no serviço social brasileiro: aproximações ao debate. Serviço Social \& Sociedade, São Paulo, ano XXVIII, n. 91, p. 110-129, 2007.

SARACHU, G. Ausências y olvidos em el debate sobre el 'tercer sector': algunas anotaciones para la reflexión del servicio social. Serviço Social \& Sociedade, São Paulo, n. 59, p. 127-151, mar. 1999.

SCHERER, E. F. Classes populares e ampliação da cidadania. Serviço Social \& Sociedade, São Paulo, n. 23, p. 32-40, 1987.

SENNA FILHO, A. R. ONG de assessoria popular, novos movimentos sociais, Estado e democracia. Serviço Social \& Sociedade, São Paulo, Ano XV, n. 45, p. 42-65, ago. 1994.

SERPA, M. A. N. A instituição sindicato é necessária hoje? Serviço Social \& Sociedade, São Paulo, n. 60, p. 87-95, 1999.

SILVA, I. M. F. da. Os Conselhos de Saúde no contexto da transição democrática: um estudo de caso. Serviço Social \& Sociedade, São Paulo, n. 55, p. 156-174, 1997.

SILVA, M. L. C. da. (Coord.) et al. Movimentos sociais e redes: refle- 


\section{tempordlis}

xões a partir do pensamento de Ilse Scherer-Warren. Serviço Social \& Sociedade, São Paulo, n. 109, p. 112-125, jan./mar. 2012.

SILVA, M. O. S. O Serviço Social e o popular: resgate teórico-metodológico do projeto profissional de ruptura. São Paulo: Cortez, 1995.

- Trinta anos da Revista Serviço Social e Sociedade: contribuições para a construção e o desenvolvimento do Serviço Social no Brasil. Serviço Social \& Sociedade, São Paulo, n. 100, p. 599-649, out./dez. 2009.

SIMIONATO, I. A concepção de hegemonia em Gramsci. Serviço Social \& Sociedade, São Paulo, n. 43, p. 99-118, 1993.

SNOW, D. A.; MULCAHY, M. Espaço, políticas e estratégias de sobrevivência dos sem-teto. Serviço Social \& Sociedade, São Paulo, n. 60, p. 60-82, 1999.

SOUZA, L. A. G. de. Lições do Fórum Social Mundial. Serviço Social \& Sociedade, São Paulo, n. 66, p. 123-145, 2001.

SOUZA, L. E.; MARTINELLI, M. L. O trabalhador no contexto dos movimentos sociais. Serviço Social \& Sociedade, São Paulo, n. 18, p. 77-93, 1985.

STEIN, R. H. A descentralização como instrumento de ação política e suas controvérsias. Serviço Social \& Sociedade, São Paulo, ano XVIII, n. 54, p. 75-96, jul. 1997.

TEIXEIRA, E. C. O papel político das associações. Serviço Social \& Sociedade, São Paulo, ano XXIII, n. 72, p. 71-90, 2002.

TEIXEIRA, J. B. O Brasil na Federação Internacional de Assistentes Sociais. Serviço Social \& Sociedade, São Paulo, n. 96, p. 89-101, 2008.

TOLEDO, L. R. Di M. C. 1968 e o cenário da resistência. Serviço Social \& Sociedade, São Paulo, n. 58, p. 67-80, 1998.

VIANA, M. R. Lutas sociais e redes de movimentos no final do século XX. Serviço Social \& Sociedade, São Paulo, ano XXI, n. 64, p. 34-56, nov. 2000. 
YACOUB, L. B. D. A luta contemporânea pela redução da jornada de trabalho: recuperando antigas bandeiras. Serviço Social \& Sociedade, São Paulo, n. 82, p. 46-72, 2005.

WANDERLEY, L. E. Os sujeitos sociais em questão. Serviço Social \& Sociedade, São Paulo, ano XIII, n. 40, p. 45-67, 1992. 
